\title{
Globe
}

Revue internationale d'études québécoises

\section{Serge Cantin et Marjolaine Deschênes (dir.) : Nos vérités sont-elles pertinentes? L'oeuvre de Fernand Dumont en perspective, Québec, Presse de l’Université Laval, 2009}

\section{Dominic Desroches}

Volume 12, numéro 2, 2009

URI : https://id.erudit.org/iderudit/1000722ar

DOI : https://doi.org/10.7202/1000722ar

Aller au sommaire du numéro

Éditeur(s)

Globe, Revue internationale d'études québécoises

ISSN

1481-5869 (imprimé)

1923-8231 (numérique)

Découvrir la revue

Citer ce compte rendu

Desroches, D. (2009). Compte rendu de [Serge Cantin et Marjolaine Deschênes (dir.) : Nos vérités sont-elles pertinentes? L'oeuvre de Fernand Dumont en perspective, Québec, Presse de l'Université Laval, 2009]. Globe, 12(2), 236-239. https://doi.org/10.7202/1000722ar d'utilisation que vous pouvez consulter en ligne.

https://apropos.erudit.org/fr/usagers/politique-dutilisation/ 


\section{Serge Cantin et Marjolaine Deschênes (dir.) \\ Nos vérités sont-elles pertinentes? \\ L'cuvre de Fernand Dumonten perspective \\ Québec, Presse de l'Université Laval, 2009.}

Il nous arrive parfois de distinguer la culture première de la culture seconde. Assez souvent encore, il nous arrive de rappeler le rôle de la distance dans la conscience de soi, la mémoire collective et l'histoire. On parle aujourd'hui des idéologies, de la nation et de l'importance de respecter la langue de la majorité sans renoncer aux « raisons communes». Quand nous utilisons ces concepts ou parlons ainsi, souvent même sans nous en rendre compte, nous trahissons notre dette à l'egard de Fernand Dumont. Si le professeur de l'Université Laval nous a quittés en 1997, ses œuvres complètes, éditées en cinq tomes l'an dernier aux presses de son alma mater, méritent de nouvelles études qui permettront de mieux baliser son héritage. Si on se rapporte aussi à la crise des accommodements raisonnables, on comprendra l'intérêt de relire Dumont afin de voir comment cette œuvre, plus d'une décennie après le décès de son auteur, peut nous aider à expliquer les problèmes identitaires qui fragmentent la société québécoise. L'œuvre de Dumont, on le voit, appelle sa redécouverte.

Dans le collectif intitulé Nos vérités sont-elles pertinentes?, Serge Cantin et Marjolaine Deschênes présentent une trentaine de textes revus pour les fins d'une publication en hommage à Dumont. À une exception près, ils sont issus du colloque international et interdisciplinaire tenu à l'Université du Québec à Trois-Rivières en mai 2007 à l'occasion du $75^{\circ}$ congrès de l'Association canadienne-française pour l'avancement des sciences (ACFAS). Le titre du livre, emprunté à Dumont, a servi de guide pour le colloque. Quand aux contributions, elles sont séparées en huit thématiques allant de l'épistémologie à la théologie, en passant par la pédagogie, l'éthique, la politique et la société québécoise. On trouvera des textes consacrés au parcours intellectuel de Dumont, lui qui a aussi été poète. L'œuvre sera donc approfondie à partir de perspectives multiples, ouvertes, axées sur la pertinence du savoir que l'homme a de lui-même. En raison du nombre élevé d'articles, nous nous bornerons à présenter quelques-uns des plus significatifs et les liens qui les unissent.

Le texte de Cantin sur la pertinence de l'anthropologie est remarquable. Si le spécialiste de Dumont retrace la genèse de cette interrogation sur la pertinence, il montre, en utilisant les écrits de Simone Weil, qu'elle 
concerne le rôle de l'intellectuel et implique par là une critique philosophique de la culture et de la société. Il précise d'un côté que les hommes habitent une culture première et, de l'autre, que les intellectuels ont tendance à se déraciner, à oublier la culture du milieu d'origine. En ce qui concerne la question de la pertinence de l'anthropologie, elle revient à se demander ce qu'il faut retenir du discours qui prend l'homme comme objet. Cet article servira de point d'ancrage au livre. À la fin de ce premier chapitre, on trouvera par ailleurs le verbatim d'un débat intéressant et fécond sur l'épistémologie dumontienne (p. 33-50).

Au sujet de la théorie de la culture, les présentations de Jacques Beauchemin et de Claude Javeau sont riches. La première étudie le problème du sens (et de la nostalgie des origines), alors que la seconde explicite ce que Dumont entend par culture. Pour Beauchemin, le défi consiste à étudier comment le dédoublement culturel conduit à une crise du sens (la production de la culture seconde ne peut traduire l'expérience de la culture première) et pourquoi la culture seconde en vient ensuite à susciter la méfiance de Dumont, notamment en raison de son éloignement de la communauté et de la mémoire collective. Dans ce cadre, Javeau présente la culture par ses "dualités" : la culture dispersée et la culture institutionnalisée, la culture première et la culture seconde évidemment, mais aussi la postmodernité et la culture troisième (p. 67-79)

Les textes du chapitre suivant reposent surtout sur des lectures de Récit d'une émigration car ils se penchent sur la genèse et la filiation de la pensée de Dumont. Micheline Cambron s'intéresse au Dumont lecteur, alors que Marc Renault cherche et trouve des références blondéliennes dans son œuvre. Si Gérard Langlade relève des paradoxes dans l'écriture autobiographique de Dumont, le lecteur tirera profit du texte de Fernand Harvey, qui s'intéresse à la question de l'américanité, puisque celui-ci retrace, depuis les études de Dumont à la Faculté des sciences sociales jusqu’à son enseignement, les influences qui ont présidé à la rédaction de Genèse de la société québécoise dans laquelle le sociologue comprend le Québec dans sa construction en tant que région limitrophe du nord des États-Unis. S'il se borne à présenter trois concepts décisifs (imaginaire, culture et idéologie) et à rappeler le modèle qu'était Bachelard, Yves Laberge, quant à lui, décrit avec précision l'atmosphère du dernier séminaire de son maître à l'Université Laval (p. 157-166).

Si Dumont a beaucoup réfléchi au système scolaire québécois, il peut être utile de relire ses textes au moment où l'on s'interroge sur les effets de la réforme et les échecs de la pédagogie socioconstructiviste. L'école pour 
lui devait transmettre des savoirs. Denis Simard et Héloïse Côté rappellent que l'école est un lieu de culture où l'elève apprend par la mise à distance de son quotidien. Ainsi, l'école perd de sa pertinence lorsqu'elle joue le jeu du marché, comme l'illustre aussi le texte de Sébastien Saint-Onge. Fidèle à Durkheim, explique-t-il, Dumont n'est jamais resté insensible aux inepties pédagogiques qui ont transformé cette institution culturelle en marché aux idéologies. Son ceuvre rappelle le rôle de la mémoire et du savoir, non sans critiquer, dans Récit d'une émigration, le "pédagogisme» en vogue qui survalorise le vécu des élèves, des "apprenants qui construisent eux-mêmes leur savoir" (p. 204), au détriment du contenu. On supprime ainsi la relation féconde entre le maître et l'étudiant, couronnement réussi d'une "aliénation socialisée» (p. 209).

Or l'œuvre de Dumont comprend des textes encore plus engagés. En effet, les écrits sociopolitiques font ressortir l'engagement de l'intellectuel pour la cause nationale tout en tissant des liens entre les principaux savoirs normatifs. Daniel Jacques, qui éclaire une partie de notre dette à l'endroit de Dumont dans La fatigue politique du Québec français, tente de rattacher l'anthropologie à la politique. Circulaire et enivrante, sa contribution résume la critique dumontienne du projet politique moderne (p. 223-225). JeanMarc Larouche se penche quant à lui sur l'idée de communauté politique en la dégageant au moyen d'idées que Jean-Marc Ferry, un lecteur de Michael Walzer, applique à l'ensemble politique européen. Pour lui, distinguer la communauté politique des communautés morale et légale permet de montrer que la Cité, dans l'esprit de Dumont, ne peut se penser sans un rapport à la transcendance, à une réalité qui nous dépasse.

Le chapitre VI porte sur la société québécoise. Celle-ci a tellement passionné Dumont qu'il a en fait une affaire personnelle, une obsession qui s'étudie entre le particulier et l'universel, comme l'illustrent les textes des historiens Julien Goyette et Yvan Lamonde. Hans-Jürgen Lüsebrinck poursuit le dialogue avec l'Europe. Il s'est intéressé à l'imaginaire de la nation en montrant comment la conception de Dumont, par sa sémantique et sa structuration (clivée par le dédoublement culturel, mais aussi par l'appréhension subjective s'opposant à l'objectivité de la nation), se distingue des conceptualisations européennes. Bousculant le multiculturalisme, l'approche de Dumont, fort actuelle, gagnerait à être nuancée par les apports d'autres chercheurs contemporains, comme Nora, Anderson, Koselleck, Jeismann, Hobsbawm et Wehler (p. 271-278).

L'ouvrage couvre enfin les champs de la poésie et de la théologie auxquels s'est aussi mesuré Dumont. Sans surprise, Marjolaine Deschênes 
retrouve des concepts classiques de l'œuvre dans les écrits poétiques, comme la distance et la mémoire. On cherche à mieux départager, dans le dernier chapitre, les liens entre le savoir et la foi. Patrice Bergeron et Pierre Lucier étudient une épistémologie de la croyance qui ne renonce pas à pointer les limites du christianisme. La philosophie et la théologie ne s'opposent pas, elles se partagent des visions de l'homme qu'il convient d'explorer à même leur mode de rupture propre. Si la théologie confere un sens à l'action, comme le souligne le texte de Robert Mager, elle veille à maintenir l'ouverture à la transcendance (p. 335).

À la fin du livre, le lecteur mesurera sans doute beaucoup mieux l'envergure et la fécondité des recherches de Dumont. Il sera peut-être étonné du silence relatif entourant cette œuvre immense et trop peu connue au Québec même. Il pourra se demander pourquoi une œuvre, forte d'autant de perspectives, construite sur plus de 40 ans d'études, n'a connu que peu d'écho au Québec et en France. Quand cette interrogation anxiogène s'apaisera enfin, il s'estimera chanceux d'avoir pu bénéficier du travail d'excellente qualité présenté ici, dont le caractère international traduit malgré tout la puissance et l'autorité de la figure de Dumont. Et comme on a pu le dire lors de la journée qui lui a été consacrée à La Maison des étudiants canadiens, à la Cité universitaire de Paris à laquelle nous avons eu l'occasion de participer - c'était en mars 2009 - si l'œuvre dumontienne reste méconnue, elle n'en continue pas moins de vibrer très longtemps, lorsqu'elle est bien lue, dans le cour de ses heureux lecteurs. Enfin, on remerciera Serge Cantin de sa persévérance, lui qui a consacré de nombreux travaux à l'un de nos plus grands penseurs ${ }^{14}$ et qui continue de faire parler, dans la cacophonie ambiante, un auteur humble dont l'œuvre s'avère primordiale pour comprendre et interpréter le Québec moderne.

Dominic Desroches Collège Ahuntsic

14. Voir, entre autres, Serge CANTTN, Fernand Dumont. Un témoin de l'Homme, Montréal, L'Hexagone, 2000. 